\title{
Relationship between the stratospheric quasi-biennial oscillation and the spring rainfall in the western North Pacific
}

\author{
Jihoon Seo, ${ }^{1,2}$ Wookap Choi, ${ }^{1}$ Daeok Youn, ${ }^{3}$ Doo-Sun R. Park, ${ }^{1}$ and Jin Young Kim ${ }^{2}$ \\ Received 7 October 2013; revised 31 October 2013; accepted 2 November 2013; published 22 November 2013.
}

[1] The effects of the stratospheric quasi-biennial oscillation (QBO) on spring rainfall in the western North Pacific (WNP) are investigated using observational and reanalysis data for 1979-2012. After excluding the strong El Niño-Southern Oscillation events, composite analyses between opposite phases of the QBO are applied to the rainfall and related meteorological fields to show the differences in each QBO phase. In comparison with the easterly phase, during the westerly QBO, a midlatitude spring rainband extending from southeastern China to the east of the Japanese Islands is displaced southward, and thus, the spring rainfall over Korea and Japan exhibits a significant decrease. Such changes in the spring WNP rainfall are related to the location and intensity of the WNP subtropical high (WNPSH) and the East Asian jet (EAJ). The possible role of the $\mathrm{QBO}$ in modulating the WNPSH and the EAJ is discussed with regard to the strength of the Hadley circulation. Citation: Seo, J., W. Choi, D. Youn, D.-S. R. Park, and J. Y. Kim (2013), Relationship between the stratospheric quasi-biennial oscillation and the spring rainfall in the western North Pacific, Geophys. Res. Lett., 40, 5949-5953, doi:10.1002/2013GL058266.

\section{Introduction}

[2] In East Asia and the western North Pacific (WNP) region, the amount of rainfall in springtime is a crucial factor for agriculture, although the amount received is less than that in the summer monsoon season. However, relatively few studies have examined the large-scale meteorological conditions related to spring rainfall over the region. It has been reported that the El Niño-Southern Oscillation (ENSO) could influence the variability of the spring rainfall in the WNP region [Wang et al., 2000; Wu et al., 2003; Chou et al., 2009]. Studies that have investigated relationships between the variability of the spring WNP rainfall and various climatic factors have included those focused on the North Atlantic Oscillation [Xin et al., 2006] and the continental snow conditions over East Asia [Choi et al., 2010]. Recently, Park et al. [2010] have reported that the spring

\footnotetext{
${ }^{1}$ School of Earth and Environmental Sciences, Seoul National University, Seoul, South Korea.

${ }^{2}$ Green City Technology Institute, Korea Institute of Science and Technology, Seoul, South Korea.

${ }^{3}$ Department of Earth Science Education, Chungbuk National University, Cheongju, South Korea.

Corresponding author: W. Choi, School of Earth and Environmental Sciences, Seoul National University, Seoul 151-747, South Korea. (wchoi@snu.ac.kr)

(C)2013. American Geophysical Union. All Rights Reserved. 0094-8276/13/10.1002/2013GL058266
}

rainfall over Northeast Asia is closely related to the intensity of the subtropical high and the meridional displacement of the subtropical jet. During spring droughts, the weakened WNP subtropical high (WNPSH) reduces the northward moisture transport into Northeast Asia, and the southward shift of the East Asian jet (EAJ) moves the frontal zone farther south [Park et al., 2010].

[3] The above mentioned variability in the spring rainfall owing to large-scale atmospheric conditions in the WNP region may be also related to the influence of the stratospheric quasi-biennial oscillation (QBO) on the troposphere. It has been reported that the equatorial $\mathrm{QBO}$ in the lower stratosphere affects the tropical deep convection [e.g., Collimore et al., 2003] and the Hadley circulation [Liess and Geller, 2012] over the western Pacific Ocean, with enhanced tropical deep convection and stronger Hadley circulation during the easterly phase of the QBO (EQBO) than the westerly phase (WQBO). Experiments using a general circulation model (GCM) with QBO forcing by Giorgetta et al. [1999] suggest that the QBO-related changes in the tropical deep convection could excite barotropic Rossby wave trains, which propagate toward the midlatitudes and subsequently modify extratropical circulations in the WNP region. This barotropic wave train over the WNP is most amplified in the outflow region of the EAJ [Giorgetta et al., 1999] and is related to the extension of the WNPSH [Ho et al., 2009]. The QBO could also affect the extratropical circulation through modulation of atmospheric wave activity interacting with the subtropical jet [e.g., Inoue et al., 2011]. Recently, Garfinkel and Hartmann [2011a, 2011b] have conducted GCM experiments with the imposed QBO and showed that interactions between temperature anomalies related to the secondary meridional circulation of the QBO and tropospheric high-frequency eddies play an important role in the meridional displacement of the subtropical jet.

[4] Despite the importance of rainfall amount over the WNP in the boreal spring, the relationships between the stratospheric QBO and the spring rainfall in East Asia have not been studied so far. In particular, previous analyses of precipitation, outgoing longwave radiation (OLR), and relevant large-scale background meteorology have not been investigated in relation with the QBO. In this study, we suggest probable influences of the QBO on the variability of the spring rainfall in the WNP region.

\section{Data and Analysis Method}

[5] To determine the phase of the QBO, $50 \mathrm{hPa}$ zonal wind over Singapore [Naujokat, 1986] is used. The zonal wind at $50 \mathrm{hPa}$ as well as the vertical wind shear is best correlated with the height and temperature of the tropical tropopause [Randel et al., 2000; Zhou et al., 2001]. Considering the 


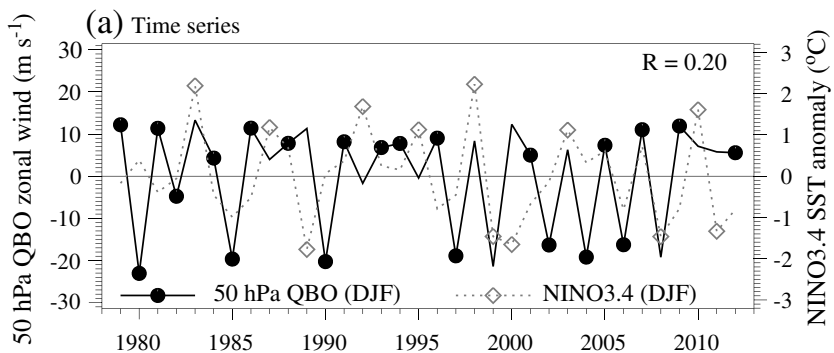

(b) Scatter plot

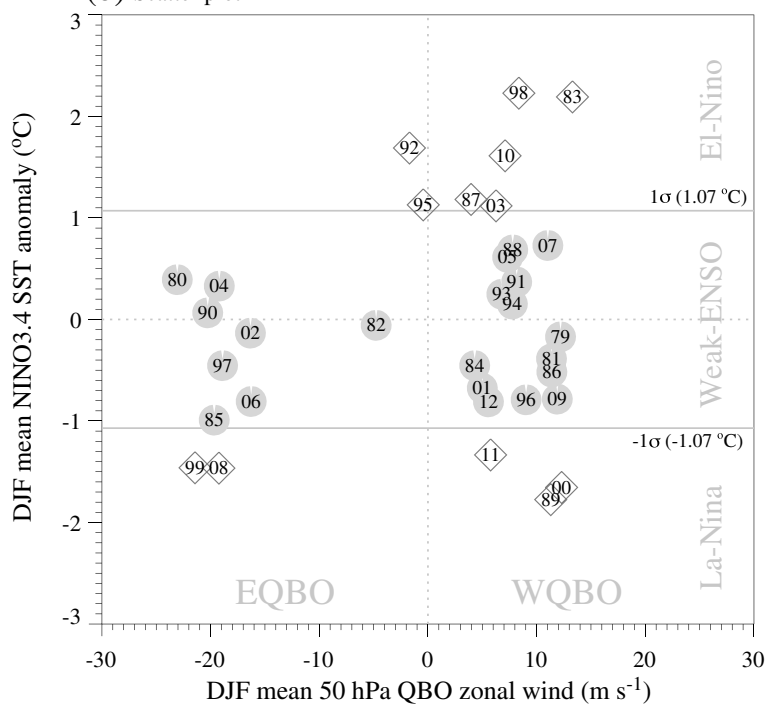

Figure 1. (a) Zonal wind at $50 \mathrm{hPa}$ over Singapore (solid line) and NINO3.4 index (dotted line) during the preceding winter (DJF) for 1979-2012. Years with a strong ENSO (NINO3.4 anomaly $>1.07^{\circ} \mathrm{C}$ ) are marked by diamonds. Solid circles mark the years chosen for analyses in this study. (b) Scatter plot of Singapore zonal wind at $50 \mathrm{hPa}$ versus NINO3.4 anomaly during DJF. Numbers marked by circles and diamonds are the years in weak and strong ENSO conditions, respectively. Gray solid horizontal lines represent one standard deviation of the NINO3.4 index.

downward propagation of the QBO-related signals to the troposphere, we averaged the zonal wind at $50 \mathrm{hPa}$ during the preceding winter (December, January, and February: DJF). The ENSO is an important factor to influence the rainfall variability in the WNP region [Wang et al., 2000; Wu et al., 2003; Chou et al., 2009], and it could also affect the QBO through changes in convective activity and excitation of equatorial waves [Geller et al., 1997; Taguchi, 2010]. Since our aim is to investigate the sole influence of the QBO, we attempt to eliminate potential influences of the ENSO by defining strong ENSO years based on the NINO3.4 index and excluding them from the analyses. Considering that the amplitude of the ENSO is large in winter, the winter (DJF) mean NINO3.4 sea surface temperature (SST) anomalies were used for the analyses.

[6] To exhibit the relationship between the QBO and the ENSO, the Singapore zonal wind at $50 \mathrm{hPa}$ and the NINO3.4 index in the preceding winter are shown in Figure 1a for the 34 year analysis period, and their scatter diagram is shown in Figure 1b. The standard deviation for the NINO3.4 SST anomalies is $1.07^{\circ} \mathrm{C}$, which is used as the threshold for the strong ENSO years. The 7 strong El Niño and 5 La Niña years are marked by diamonds in Figure 1. In Figure 1b, zonal winds in EQBO and WQBO years in the weak ENSO years are well separated, and thus, we defined WQBO and EQBO years by the composites of 14 and 8 years out of 22 weak ENSO years (in solid circle), respectively. The correlation between the QBO and the ENSO during this 22 year period is negligible $(R=0.06)$, although the correlation for the entire 34 year period is a much higher value of 0.20 (Figure 1a). The mean NINO3.4 anomalies for the WQBO and EQBO composites are $-0.13^{\circ} \mathrm{C}$ and $-0.21^{\circ} \mathrm{C}$, respectively. These two values

(a) Precip (mm day $\left.{ }^{-1}\right) \quad$ [Spring (MAM) climatology]

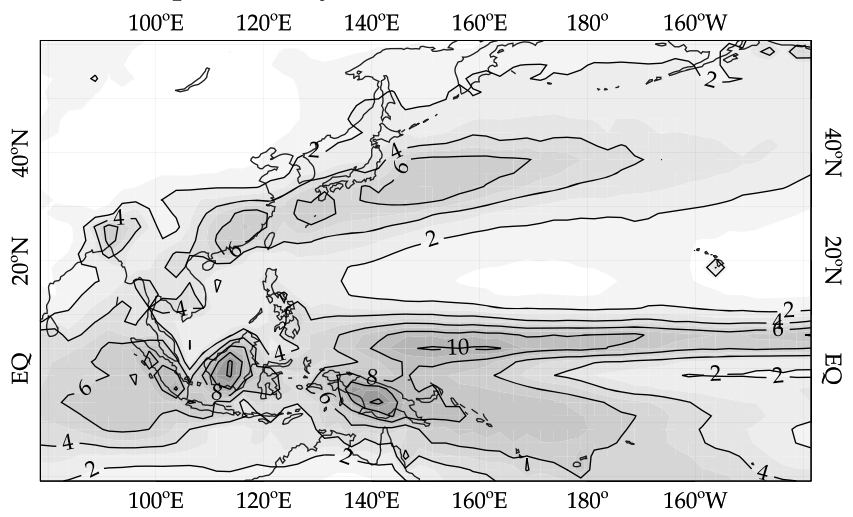

(b) $\Delta$ Precip $\left(m m\right.$ day $\left.^{-1}\right)$

[WQBO-EQBO]

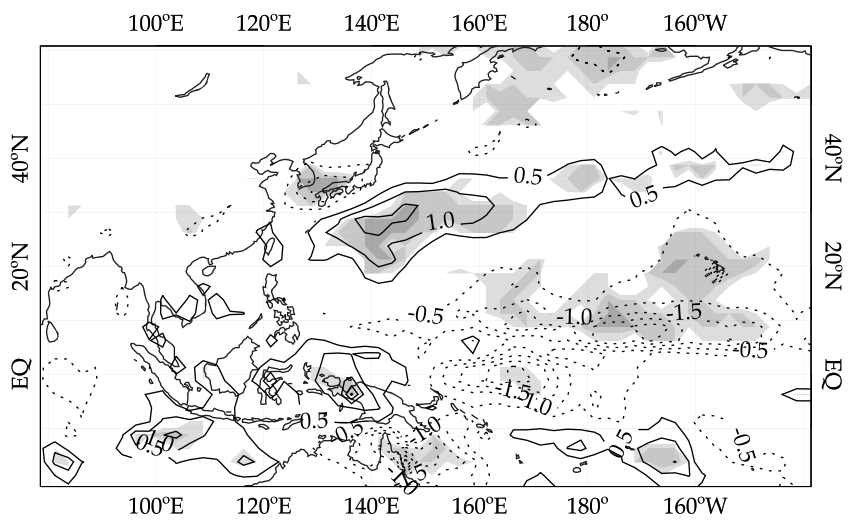

(c) $\triangle \mathrm{OLR}\left(10^{2} \mathrm{~W} \mathrm{~m}^{-2}\right)$

[WQBO-EQBO]

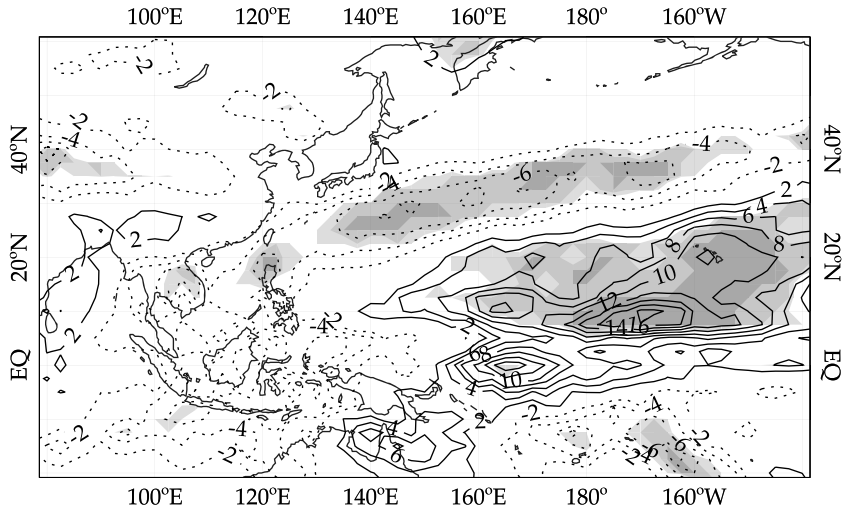

Figure 2. (a) Climatological mean spring (MAM) precipitation for 1979-2012 and composite differences of (b) precipitation and (c) OLR between the WQBO and the EQBO during MAM. Light, medium, and dark shading indicates the $90 \%, 95 \%$, and $99 \%$ confidence levels, respectively. Zero lines are omitted in Figures $2 \mathrm{~b}$ and $2 \mathrm{c}$. 
(a) $\Delta \mathrm{Z}$ at $850 \mathrm{hPa}(\mathrm{gpm})$

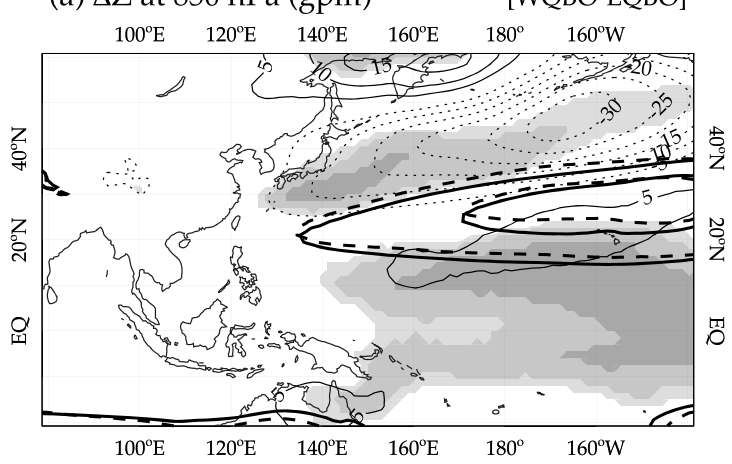

(c) $\Delta \mathrm{u}$ at $200 \mathrm{hPa}\left(\mathrm{m} \mathrm{s}^{-1}\right)$

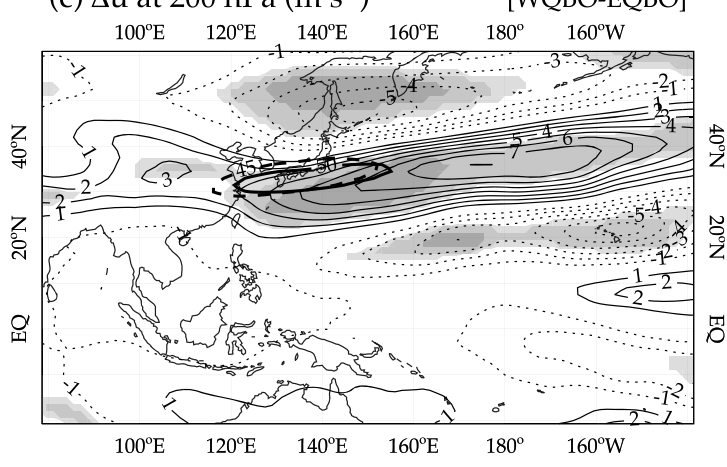

(b) $\Delta \mathrm{q}\left(\mathrm{kg} \mathrm{m}^{-2}\right)$

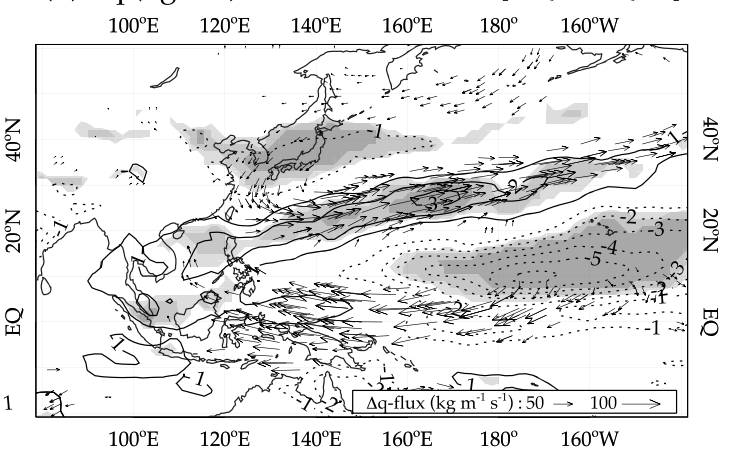

(d) $\Delta \mathrm{T}$ at $500 \mathrm{hPa}(\mathrm{K})$

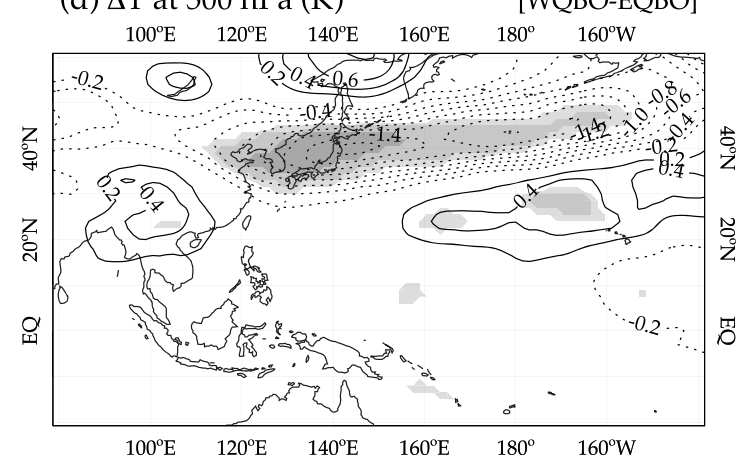

Figure 3. Composite differences of (a) geopotential height $(Z)$ at $850 \mathrm{hPa}$, (b) vertically integrated (1000-100 hPa) moisture content $(q)$ and its flux, (c) zonal wind $(u)$ at $200 \mathrm{hPa}$, and (d) temperature $(T)$ at $500 \mathrm{hPa}$ between the WQBO and the EQBO in spring (MAM). Zero lines are omitted. Light, medium, and dark shading indicates the $90 \%, 95 \%$, and $99 \%$ confidence levels, respectively. Thick solid (dashed) contours in Figure 3a denote the composite means of 1520 and $1540 \mathrm{~m}$ during the WQBO (EQBO). Difference vectors of the moisture flux in Figure $3 \mathrm{~b}$ are significant at the $95 \%$ confidence level. The thick solid (dashed) contour in Figure $3 \mathrm{c}$ denotes the composite mean of $50 \mathrm{~m} \mathrm{~s}^{-1}\left(45 \mathrm{~m} \mathrm{~s}^{-1}\right)$, which represents the core of the EAJ during the WQBO (EQBO).

are much smaller than the standard deviation of the NINO3.4 index. Considering the correlation and the means described above, the potential contamination of the QBO-related signals by the ENSO seems to be negligible.

[7] The rainfall data used in this study are the Global Precipitation Climatology Project merged gauge-satellite monthly precipitation [Adler et al., 2003] for the period 1979-2012. As proxies for vertical motion and deep convection, we used the National Oceanic and Atmospheric Administration monthly OLR [Liebmann and Smith, 1996] for the same period. For the monthly fields of temperature, horizontal wind, geopotential height, and specific humidity, the European Centre for Medium-Range Weather Forecasts Re-Analysis Interim [Dee et al., 2011] is used for the same period. Since the spring rainfall in the WNP region is our main interest, all the above mentioned monthly variables are averaged through March, April, and May (MAM).

[8] We examine the influence of the stratospheric QBO on rainfall, OLR, and atmospheric variables in spring, based on differences between the composite means for each phase of the QBO (WQBO minus EQBO). Since the sample numbers for the two composite means are different, we adopt Welch's $t$ test to examine the statistical significance for the composite differences, following Inoue et al. [2011].

\section{Results}

[9] There are two major rainfall regions in the boreal spring, as shown in Figure 2a: a southwest-northeast tilting rainband associated with the midlatitude frontal zone extending from southeastern China to the east of the Japanese Islands and a tropical convective rainfall region over the maritime continent, western Pacific warm pool, and Intertropical Convergence Zone (ITCZ) [Chou et al., 2009]. In the composite difference of precipitation shown in Figure $2 b$, there is a significant positive difference to the south of the midlatitude rainband $\left(20^{\circ} \mathrm{N}-40^{\circ} \mathrm{N}, 130^{\circ} \mathrm{E}-150^{\circ} \mathrm{W}\right)$ and a significant negative difference to the north of the rainband center $\left(30^{\circ} \mathrm{N}-40^{\circ} \mathrm{N}, 120^{\circ} \mathrm{E}-\right.$ $140^{\circ} \mathrm{E}$ ) between the WQBO and the EQBO. These differences exhibit the southward (northward) displacement of the midlatitude rainband during the WQBO (EQBO) and imply subsequent decreases (increases) in the spring rainfall over Korea and Japan. Rainfall deficit in Korea during the WQBO (Figure 2b) is also exhibited in the rain gauge data measured at 60 stations in South Korea for 1979-2012 by the Korean Meteorological Administration. The correlation coefficient between the gauge-measured rainfall in spring and the $50 \mathrm{hPa}$ Singapore wind in preceding winter is -0.42 , which is statistically significant at the $95 \%$ confidence level.

[10] Similarly to previous studies [e.g., Liess and Geller, 2012], a significant negative difference in precipitation is also found at the north of the western Pacific ITCZ $\left(5^{\circ} \mathrm{N}-25^{\circ} \mathrm{N}\right.$, $160^{\circ} \mathrm{E}-140^{\circ} \mathrm{W}$ ), which implies reduced (increased) convective rainfall over the region during the WQBO (EQBO). The composite differences in OLR (Figure 2c) show similar patterns with opposite signs to those for rainfall. Since OLR is related to vertical motion and tropical deep convection, the positive (negative) differences in Figure 2c indicate weakening 
(a) $\chi$ at $200 \mathrm{hPa}\left(10^{6} \mathrm{~m}^{2} \mathrm{~s}^{-1}\right)$

[Spring (MAM) climatology]

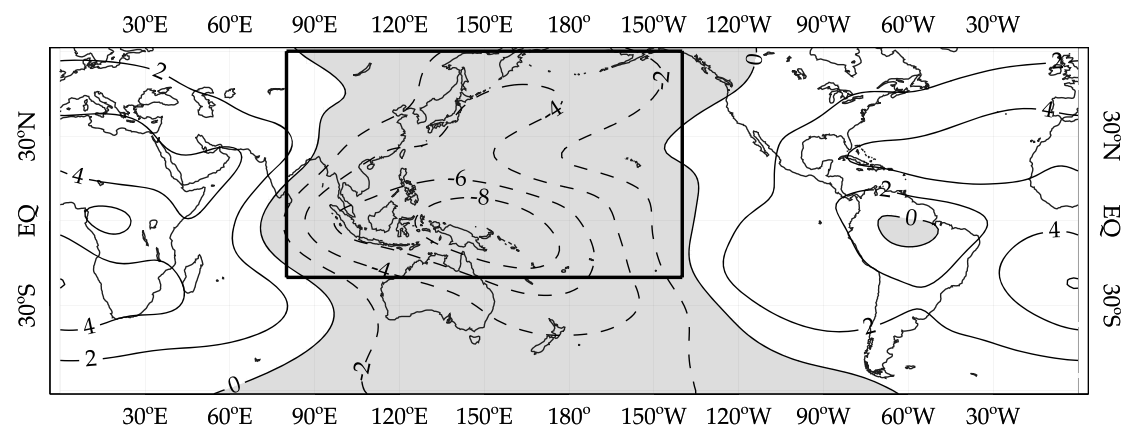

(b) $\Delta \chi$ at $200 \mathrm{hPa}\left(10^{6} \mathrm{~m}^{2} \mathrm{~s}^{-1}\right)$

[WQBO-EQBO]

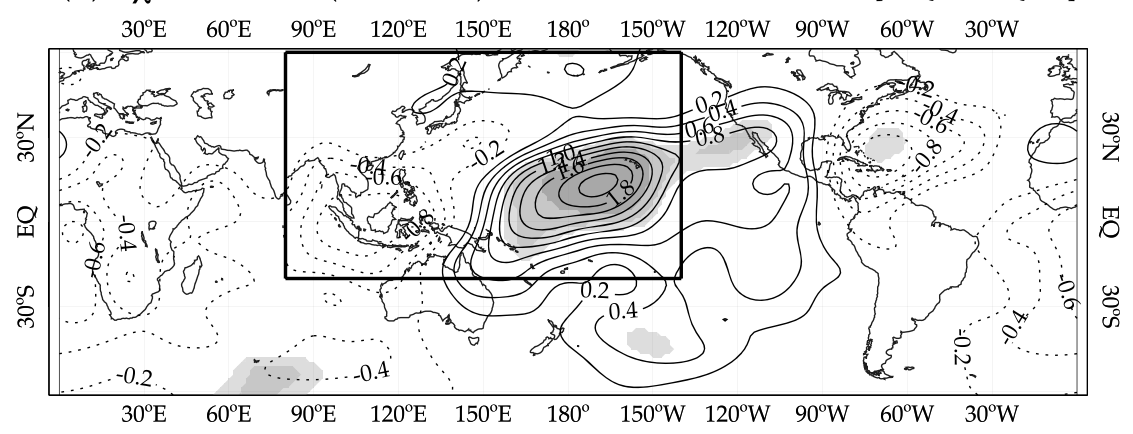

Figure 4. (a) Climatological mean spring (MAM) velocity potential $(\chi)$ at $200 \mathrm{hPa}$ for 1979-2012 with shaded negative values. (b) Composite difference of the velocity potential at $200 \mathrm{hPa}$ between the WQBO and the EQBO during MAM. Light, medium, and dark shading indicates the $90 \%, 95 \%$, and $99 \%$ confidence levels, respectively. The boundary of the domain plotted in Figures 2 and 3 is marked by a thick solid box.

(strengthening) of the vertical motion and are consistent with the reduced (increased) precipitation in Figure $2 b$.

[11] The above mentioned differences in the rainfall and OLR between the two QBO phases are accompanied by differences in other meteorological fields. In particular, the midlatitude spring rainband over the WNP is associated with convergence of the horizontal moisture flux along the northwestern boundary of the WNPSH and the frontal zone near the EAJ core [Chou et al., 2009; Park et al., 2010]. Thus, we examine the QBO-related changes in the background meteorological fields related to the WNPSH and the EAJ; the results are shown in Figure 3. In the composite differences in the geopotential height at $850 \mathrm{hPa}$ (Figure 3a), a significant low-pressure region to the east of the Japanese Islands $\left(30^{\circ} \mathrm{N}-50^{\circ} \mathrm{N}, 140^{\circ} \mathrm{E}-160^{\circ} \mathrm{W}\right)$ accompanies two highpressure regions to the north and the south, thereby exhibiting a wave train pattern. Such a pattern is also shown at the 500 and $200 \mathrm{hPa}$ levels (not shown here) and has a barotropic structure with maximum amplitude in the outflow region of the EAJ (Figure 3c) similar to Giorgetta et al. [1999, Figure 6]. This barotropic wave train is related to the location and intensity of the WNPSH [Ho et al., 2009]. The large negative differences at midlatitudes and the small positive differences at low latitudes in Figure $3 \mathrm{a}$ indicate the equatorward (poleward) displacement of the WNPSH during the WQBO (EQBO), which are exhibited by the 1520 and $1540 \mathrm{~m}$ isopleths of the composite means (thick solid and dashed contours).

[12] The displacement and the resultant change in the location of the WNPSH should be related to the horizontal moisture transport along its boundary. Figure $3 \mathrm{~b}$ shows the vertically integrated moisture content and its horizontal flux. An increased moisture flux convergence is located south of the midlatitude rainband region $\left(20^{\circ} \mathrm{N}-40^{\circ} \mathrm{N}, 130^{\circ} \mathrm{E}-140^{\circ} \mathrm{W}\right)$ in the confluent region between the anomalous low and high (Figure $3 \mathrm{a}$ ). This results in more humid conditions over the region during the WQBO than during the EQBO. Therefore, the positive rainfall and the negative OLR anomalies in Figure 2 are associated with the anomalous moisture condition. On the other hand, divergence of the southward moisture flux anomalies along the Japanese Islands leads to drier conditions over Korea and Japan, which are associated with the negative rainfall anomaly in the region during the WQBO.

[13] In addition to changes in the WNPSH, the meridional displacement of the EAJ is also related to the location of the midlatitude rainband [Park et al., 2010]. The composite differences in the zonal wind at $200 \mathrm{hPa}$ (Figure 3c) exhibit an easterly region at about $50^{\circ} \mathrm{N}$ and a westerly region at about $30^{\circ} \mathrm{N}$, which indicate a southward (northward) shift of the EAJ during the WQBO (EQBO). The spatial patterns in Figure 3c are similar to Garfinkel and Hartmann [2011b, Figures 1 and 6], which conducted GCM experiments with the imposed QBO and the fixed SSTs. These similarities suggest that contamination from the ENSO is not the dominant factor in the current QBO-related signals.

[14] The meridional displacement of the EAJ is closely related to the changes in midtropospheric temperature and its meridional gradient by the thermal wind relationship. Figure $3 \mathrm{~d}$ shows a significant decrease (increase) in temperature at $500 \mathrm{hPa}$ over Northeast Asia and extratropical North Pacific $\left(30^{\circ} \mathrm{N}-50^{\circ} \mathrm{N}, 110^{\circ} \mathrm{E}-150^{\circ} \mathrm{W}\right)$ during the WQBO (EQBO). Such difference in midtropospheric temperature 
is related to the meridional shift of the WNPSH and the horizontal thermal advection.

[15] It is noted that such anomalous patterns of the geopotential height and upper level zonal wind fields in Figure 3 are similar to atmospheric conditions during the spring drought over Northeast Asia, as noted by Park et al. [2010, Figures 3 and 5]. This implies that the QBO could be one of the possible factors influencing the spring rainfall variability over the region.

[16] To investigate the possible influences of the QBO on the large-scale circulation in the tropical and WNP regions, the velocity potential field at $200 \mathrm{hPa}$ is shown in Figure 4 . The velocity potential at $200 \mathrm{hPa}$ has been used to diagnose the location and intensity of the Hadley circulation in previous studies [e.g., Tanaka et al., 2004; Liess and Geller, 2012], since negative values are associated with large-scale divergence in the upper troposphere. The spring climatology of the velocity potential at $200 \mathrm{hPa}$ (Figure 4a) shows negative values centered over the western Pacific warm pool region, which corresponds to the region of the rising branch of the Hadley circulation. In the composite difference of the velocity potential (Figure 4b), a region of significant positive values is located over the equatorial western and central Pacific $\left(10^{\circ} \mathrm{S}-30^{\circ} \mathrm{N}, 160^{\circ} \mathrm{E}-140^{\circ} \mathrm{W}\right)$ where the OLR difference exhibits large positive values (Figure 2c). This indicates that tropical deep convection is significantly weakened (strengthened) over the region, and thus, its contribution to the meridional overturning of the Hadley circulation is decreased (increased) during the WQBO (EQBO) [Collimore et al., 2003; Liess and Geller, 2012]. The weakening of the Hadley circulation during the WQBO induces the equatorward retreat of the WNPSH, which leads to a decrease in midtropospheric temperature in the midlatitudes and the southward displacement of the EAJ by the thermal wind relationship.

\section{Conclusions}

[17] In this study the influence of the lower stratospheric QBO on the interannual variability of the spring rainfall over the WNP region was investigated. Spring (MAM) data were separated into the years of WQBO and EQBO based on the zonal wind over Singapore at $50 \mathrm{hPa}$ during the preceding winter (DJF). Composite-mean data for the WQBO and the EQBO were obtained for the analysis after excluding the strong ENSO years, when the winter NINO3.4 index exceeds its one standard deviation.

[18] Differences in spring rainfall and OLR between the opposite phases of the QBO revealed that the midlatitude rainband extending from southeastern China to the east of the Japanese Islands is displaced southward, and thus, the spring rainfall over Korea and Japan is significantly decreased during the WQBO compared to the EQBO. These QBOrelated changes in the spring WNP rainfall are closely related to changes in the large-scale meteorological fields. The lower stratospheric QBO possibly affects the subtropical high (WNPSH) and the subtropical jet (EAJ) by modifying the strength of the Hadley circulation and following the changes in pressure and temperature fields over the WNP region. The WNPSH moves equatorward during the WQBO compared to the EQBO, and the convergence region of the moisture flux along the northwestern boundary of the WNPSH is displaced southward. In addition, the EAJ associated with the midlatitude frontal zone also shifts slightly southward during the WQBO compared to the EQBO. The results of this study may improve the seasonal predictability of the spring rainfall over the Northeast Asia and WNP regions. A realistic inclusion of the QBO in dynamical or statistical models could be an important factor for seasonal forecasts.

[19] Acknowledgments. We thank K.-Y. Kim and G.-H. Lim for the helpful discussion and two anonymous reviewers for their constructive comments. This study has been funded by the Korea Institute of Science and Technology and the Ministry of Oceans and Fisheries of South Korea. Also, this study has been conducted within the government project "Quantitative assessment for PM \& BC to climate change and development of reduction technology for PM, BC from ships." Wookap Choi was supported by the NRF (2009-0052661), and Daeok Youn was supported by Chungbuk National University.

[20] The Editor thanks an anonymous reviewer and Chaim Garfinkel for their assistance in evaluating this paper.

\section{References}

Adler, R. F., et al. (2003), The version 2 Global Precipitation Climatology Project (GPCP) monthly precipitation analysis (1979-present), J. Hydrometeorol., 4, 1147-1167.

Choi, K.-S., D.-W. Kim, and H.-R. Byun (2010), The regime shift in the early 1980 s of spring precipitation in Korea, Int. J. Climatol., 30, 721-732.

Chou, C., L.-F. Huang, J.-Y. Tu, L. Tseng, and Y.-C. Hsueh (2009), El Niño impacts on precipitation in the western North Pacific-East Asian sector, J. Clim., 22, 2039-2057.

Collimore, C. C., D. W. Martin, M. H. Hitchman, A. Huesmann, and D. E. Waliser (2003), On the relationship between the QBO and tropical deep convection, J. Clim., 16, 2552-2568.

Dee, D. P., et al. (2011), The ERA-Interim reanalysis: Configuration and performance of the data assimilation system, Q. J. R. Meteorol. Soc., 137, 553-597.

Garfinkel, C. I., and D. L. Hartmann (2011a), The influence of the quasibiennial oscillation on the troposphere in winter in a hierarchy of models. Part I: Simplified dry GCM runs, J. Atmos. Sci., 68, 1273-1289.

Garfinkel, C. I., and D. L. Hartmann (2011b), The influence of the quasibiennial oscillation on the troposphere in winter in a hierarchy of models. Part II: Perpetual winter WACCM runs, J. Atmos. Sci., 68, 2026-2041.

Geller, M. A., W. Shen, M. Zhang, and W.-W. Tan (1997), Calculations of the stratospheric quasi-biennial oscillation for time-varying wave forcing, J. Atmos. Sci., 54, 883-894.

Giorgetta, M. A., L. Bengtsson, and A. K. Arpe (1999), An investigation of QBO signals in the East Asian and Indian monsoon in GCM experiments, Clim. Dyn., 15, 435-450.

Ho, C.-H., H.-S. Kim, J.-H. Jeong, and S.-W. Son (2009), Influence of stratospheric quasi-biennial oscillation on tropical cyclone tracks in western North Pacific, Geophys. Res. Lett., 36, L06702, doi:10.1029/2009GL037163.

Inoue, M., M. Takahashi, and H. Naoe (2011), Relationship between the stratospheric quasi-biennial oscillation and tropospheric circulation in northern autumn, J. Geophys. Res., 116, D24115, doi:10.1029/2011JD016040.

Liebmann, B., and C. A. Smith (1996), Description of a complete (interpolated) outgoing longwave radiation dataset, Bull. Am. Meteorol. Soc., 77, $1275-1277$.

Liess, S., and M. A. Geller (2012), On the relationship between QBO and distribution of tropical deep convection, J. Geophys. Res., 117, D03108, doi:10.1029/2011JD016317.

Naujokat, B. (1986), An update of the observed quasi-biennial oscillation of the stratospheric winds over the tropics, J. Atmos. Sci., 43, 1873-1877.

Park, J.-S., J.-G. Jhun, and M.-H. Kwon (2010), Prominent features of largescale atmospheric circulation during spring droughts over northeast Asia, Int. J. Climatol., 30(8), 1206-1214.

Randel, W. J., F. Wu, and D. J. Gaffen (2000), Interannual variability of the tropical tropopause derived from radiosonde data and NCEP reanalyses, J. Geophys. Res., 105(D12), 15,509-15,523.

Taguchi, M. (2010), Observed connection of the stratospheric quasi-biennial oscillation with El Niño-Southern Oscillation in radiosonde data, J. Geophys. Res., 115, D18120, doi:10.1029/2010JD014325.

Tanaka, H. L., N. Ishizaki, and A. Kitoh (2004), Trend and interannual variability of Walker, monsoon and Hadley circulations defined by velocity potential in the upper troposphere, Tellus, Ser. A, 56, 250-269.

Wang, B., R. Wu, and X. Fu (2000), Pacific-East Asian teleconnection: How does ENSO affect East Asian climate?, J. Clim., 13, 1517-1536.

Wu, R., Z.-Z. Hu, and B. P. Kirtman (2003), Evolution of ENSO-related rainfall anomalies in East Asia and the processes, J. Clim., 16, 3741-3757.

Xin, X., R. Yu, T. Zhou, and B. Wang (2006), Drought in late spring of South China in recent decades, J. Clim., 19, 3197-3206.

Zhou, X., M. A. Geller, and M. Zhang (2001), Tropical cold point tropopause characteristics derived from ECMWF reanalyses and soundings, J. Clim., 14, 1823-1838. 